\title{
Taxonomies in Education: Overview, Comparison, and Future Directions
}

\author{
Jeff Irvine ${ }^{1}$ \\ ${ }^{1}$ Georgetown, Ontario, Canada \\ Correspondence: Jeff Irvine, Georgetown, Ontario, Canada. E-mail: dr.jeffrey.irvine@bell.net
}

Received: April 1, 2021

Accepted: April 30, 2021

Online Published: May 14, 2021

doi:10.20849/jed.v5i2.898

URL: https://doi.org/10.20849/jed.v5i2.898

\begin{abstract}
This paper compares and contrasts some of the most popular taxonomies used in education, including: original Bloom's taxonomy, revised Bloom's taxonomy, Webb's depth of knowledge, SOLO taxonomy, Fink's taxonomy of significant learning, Shulman's table of learning, and Marzano's taxonomy. After a brief outline of each taxonomy, the paper discusses the literature corresponding to their use in education and the taxonomies are compared with regard to their treatment of knowledge, cognition, metacognition, higher-order thinking skills, affect, and explicit or implied theories of learning underlying each taxonomy. This is followed by a discussion of future directions for taxonomies in education. To date, while a few binary comparisons of taxonomies have been published, there has been no broad comparison of what may be regarded as the major taxonomies in use in education today. This paper represents the first broad examination of taxonomies that have had significant impacts on higher education.
\end{abstract}

Keywords: taxonomy, Bloom, Webb, Fink, Shulman, Marzano, SOLO

\section{Introduction}

Despite a plethora of educational taxonomies, few studies have compared the attributes of the most common ones, such as Irvine's (2017a) comparison of revised Bloom's taxonomy to Marzano's new taxonomy. This paper used content analysis (Krippendorff, 2013) to examine some well-known taxonomy in education: Bloom's, revised Bloom, the SOLO taxonomy, Webb's depth of knowledge framework, Fink's taxonomy of significant learning, Shulman's table of learning, and Marzano's new taxonomy. The taxonomies were selected for comparison based on their frequency of internet references and the breadth of their application to education. Each taxonomy serves a different purpose; was created to address different educational goals; has strengths and weaknesses; differs in the treatment of key concepts such as knowledge, cognition, and affect; has had varying degrees of application to other areas of education; is based on different theories of learning; and has varied degrees of implication for teaching and learning.

A taxonomy is summarily defined as a "classification into ordered categories" (Dictionary.com, n.d., para. 2). Typically, taxonomies consist of non-overlapping categories organized across one or more dimensions; however, in addition to categorizing concepts and information, taxonomies help identify or reveal relationships among the taxa. Shulman (2004) lists multiple uses of taxonomies - classification systems; elements to be balanced, such as the four food groups; lexicon or vocabulary; assessment frameworks; design frameworks; protocols for analysis; middle-range theories; checklists; heuristics; mnemonics; ideologies; and moral codes-all elements to be played with.

Taxonomies are ubiquitous in education. In their revision of Bloom's taxonomy, Anderson and Krathwohl (2001) examined 19 different taxonomies. This does not count numerous "special purpose" taxonomies focusing on a single aspect of learning. For example, DeBellis and Golding (2006) augmented the seminal work of McLeod (1992) to produce a taxonomy illustrating the growth of values, shown in Figure 1. This is a bottom-up, hierarchical taxonomy illustrating that values grow initially from emotional responses, which collectively form attitudes; aggregated attitudes in turn result in beliefs, and accumulated beliefs result in the devleopment of values.

Another example of a special purpose taxonomy in education is the metacognitive taxonomy developed by Meijer et al. (2006), shown in Figure 2. In their metacognitive taxonomy, each taxon includes general as well as specific strategies for text-studying and for problem-solving. For example, under Planning, general strategies 
include "look for particular information in text," "subgoaling," and "using external source to get explanation" (p. 235) while specific strategies for text-studying include "reading notes," "change of strategy by reversing arguments," and "deciding to read difficult parts of text again"; for problem-solving, specific strategies include "backward reasoning," "changing units," and "formulate action plan" (p. 235). This is a top-down, hierarchical taxonomy based on chronology; the taxa are dealt with chronologically, in a logical progression.

Taxonomies such as this one, based on a chronological hierarchy, are very similar to heuristics such as Polya's (1957) well-known problem-solving heuristic (Figure 3) or the Harvard University (2003) Balanced Assessment project's extended mathematical problem-solving heuristic (Figure 4).

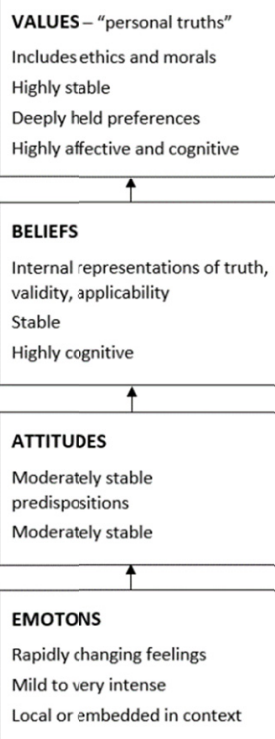

ATTITUDES

Moderately stable

EMOTONS

Rapidly changing feelings

Mild to very intense

Local or embedded in context

Figure 1. Taxonomy linking emotions, attitudes, beliefs, and values; based on DeBellis and Golding (2006)

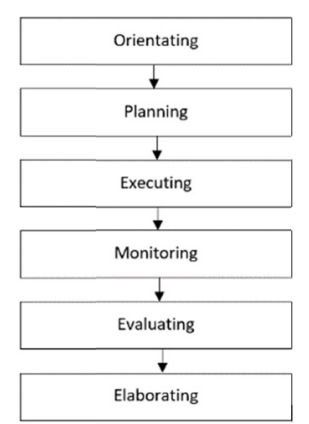

Figure 2. Metacognitive taxonomy; based on Meijer et al. (2006)

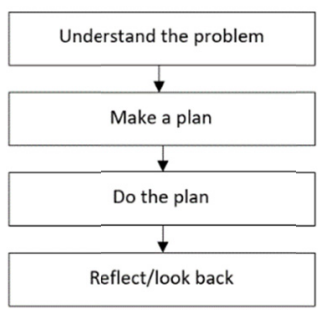

Figure 3. Polya's (1957) problem-solving heuristic 


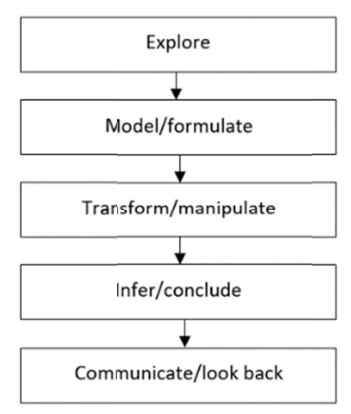

Figure 4. Mathematical problem-solving hierarchy; based on Harvard University's (2003) Balanced Assessment project

Other taxonomies in education may be hierarchical based on complexity. An example of such a taxonomy is the SAMR taxonomy (Puentedura, 2006, 2009), which examines applications of technology (Figure 5).

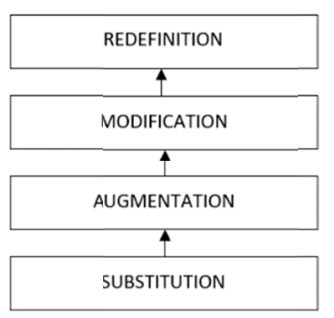

Figure 5. SAMR taxonomy (Puentedura, 2006)

The SAMR taxonomy is bottom-up based on the role of technology. The bottom level is substitution, in which new technology is used to perform the same task as was previously done, either with or without technology. For example, a learning task previously done using a graphing calculator would now be done using a computer program, but the task remains the same. In the second level, augmentation, the new technology is a direct substitute for old technology, but with functional improvement. An example could be the use of computer algebra systems (CAS) to supplement paper-and-pencil algebraic manipulations. At the modification level, the new technology allows for significant redesign of tasks. Computer animation could be used to illustrate the impact of transforming graphs of functions by varying parameters in the equation of the function. Finally, at the top level, redefinition, the technology allows for the creation of new tasks that would not have been possible without the technological advance. An early example of this was the impact of scientific calculators to replace printed tables or paper-and-pencil calculations of mortgage payments. The use of calculators enabled consideration of "what if?" scenarios based on changes in interest rates or the value of balloon payments against mortgage principle; this could not have been done using the former technology. The SAMR taxonomy has been widely used in education and numerous other fields.

\section{Overview of the Taxonomies}

The taxonomies described below have had significant impact on education. Some, like the seminal Bloom's taxonomy, are very well known. Other, more recent taxonomies, reflect the growth in knowledge concerning student learning and the concomitant development of teaching strategies to reflect that knowledge.

\subsection{Bloom's Taxonomy}

By far the most widely known taxonomy is the original Bloom's taxonomy (OBT). Taxonomy of Educational Objectives: The Classification of Educational Goals-Handbook I, Cognitive Domain (Bloom et al., 1956) was developed through years of collaboration among the Committee of College and University Examiners. The taxonomy was designed to help examiners classify assessment items by level of cognitive demand. OBT was planned as the first of three volumes, to be followed by taxonomies of affective and psychomotor domains, respectively. OBT has had an impressive 65-year impact on education. An internet search for "Bloom's 
taxonomy" returned 43.8 million results (although some results refer to the revised version of the taxonomy), far more than any other taxonomy searched.

OBT consists of six levels (Figure 6) and is a cumulative bottom-up hierarchy, in which mastery of each level is assumed before proceeding to the next level. Each level comprises verbs associated with questions corresponding to each level of difficulty. Sample verbs are shown in Table 1.

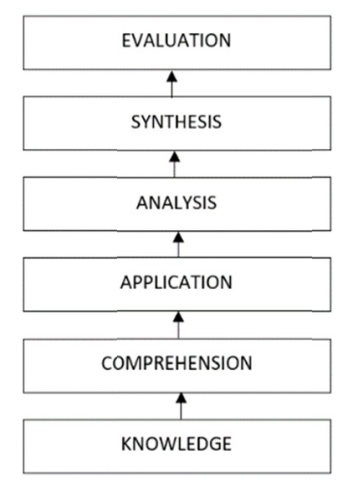

Figure 6. Original Bloom's taxonomy (OBT: Cognitive domain; OBT-C)

Table 1. Verbs associated with the levels of OBT

\begin{tabular}{ll}
\hline Evaluation & appraise, assess, criticize, defend, evaluate, justify, support \\
\hline Synthesis & create, develop, generalize, integrate, propose, compile \\
\hline Analysis & compare, contrast, differentiate, analyze \\
\hline Application & apply, carry out, demonstrate, produce, construct, operate, produce, use \\
\hline Comprehension & describe, discuss, distinguish, comprehend, locate, interpret \\
\hline Knowledge & name, list, describe, outline, recall, identify, label, recognize, reproduce, state, match, select \\
\hline
\end{tabular}

The extensive focus on OBT (cognitive domain) may reflect the assessment practices of the era in which it was created, whereby university evaluations were almost exclusively assessments of cognitive dimensions. Uses of OBT quickly moved beyond categorizing assessment questions to designing courses, specifying learning objectives, and modifying existing courses to ensure they addressed all six taxa. There is a myriad of examples of applications of OBT, as can be inferred from the almost 44 million internet search results. OBT has been applied extensively to: create learning objectives (Adams, 2015; Arievitch, 2020) and course design (Betts, 2008; Pappas et al., 2013; Tyran, 2010); evaluate assessment items (Kim et al., 2012; Meissner et al., 2002; Morton \& Colbert-Getz, 2017; Oliver et al., 2004); and identify higher-order thinking skills (HOTS; Irvine et al., 2016; Johansson, 2020; Kantar, 2014; Madhuri et al., 2012; McBain, 2011; Sagala \& Andriani, 2019; van de Heyde \& Siebrits, 2019). All of these uses of OBT include both higher education and secondary education.

In 1964, Bloom et al. produced Taxonomy of Educational Objectives: The Classification of Educational Goals-Handbook II, Affective Domain, which included an affective taxonomy (Figure 7). This is a cumulative top-down taxonomy, with sublevels and descriptions shown in Table 2.

While the affective taxonomy is less widely known than OBT, there are several notable applications of the affective taxonomy in education. For example, Muzyk et al. (2017) utilized OBT affective domain (OBT-A) to influence stigmatizing attitudes of pharmacy students; Ugur et al. (2015) blended OBT-A with self-determination theory in addressing personal growth and self-awareness in course design; Dollarhide (2013) based a counselling education course on OBT-A to address spiritual, ethical, and religious counselling. One major application of OBT-A was in the development of mathematical well-being (MWB). 


\subsubsection{Mathematical Well-being (MWB)}

Clarkson et al. (2010) developed a taxonomy of MWB by combining OBT-A, OBT cognitive (OBT-C), and an emotional taxonomy shown in Figure 8 and further described in Table 3. Of note is that the emotional taxonomy explicitly indicates how the levels link together.

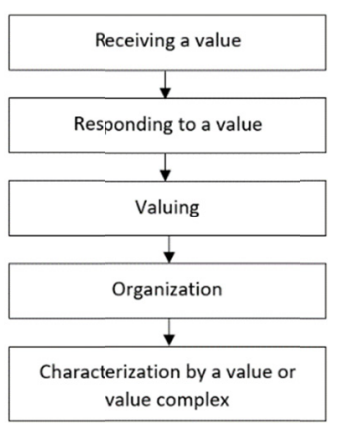

Figure 7. OBT affective domain (OBT-A); from Bloom et al. (1964, p. 35)

Table 2. OBT affective domain (OBT-A)

\begin{tabular}{lll}
\hline Taxon & Sublevels & Descriptors \\
\hline Receiving a value & & \\
\hline & Awareness & Attends to the stimulus \\
\hline & Willingness to receive & Demonstrates a willingness to consider the stimulus \\
\hline Responding & Controlled or selected attention & Looks for the stimulus \\
\hline \multicolumn{5}{c}{ Acquiescence } \\
\hline Willingness to respond & $\begin{array}{l}\text { Responds to the stimulus; complies } \\
\text { expectations }\end{array}$ \\
\hline Valuing & Satisfaction in response & Responds with increased inner interest \\
\hline \multicolumn{5}{c}{ Acceptance of a value } & Adopts the value and acts accordingly \\
\hline Preference for a value & Seeks out examples of the value \\
\hline Organization & Commitment/conviction & Demonstrates conviction in the value \\
\hline \multicolumn{5}{c}{$\begin{array}{l}\text { Characterization by } \\
\text { complex }\end{array}$} & Conceptualization of a value & Conceptualizes how the value fits with life \\
\hline & Organization of a value system & Merges new value with other life values \\
\hline & Generalized set & \\
\hline & Characterization & $\begin{array}{l}\text { Develops a consistent philosophy of life based on the } \\
\text { value }\end{array}$ \\
\hline
\end{tabular}

From Bloom et al. (1964, p. 35). 


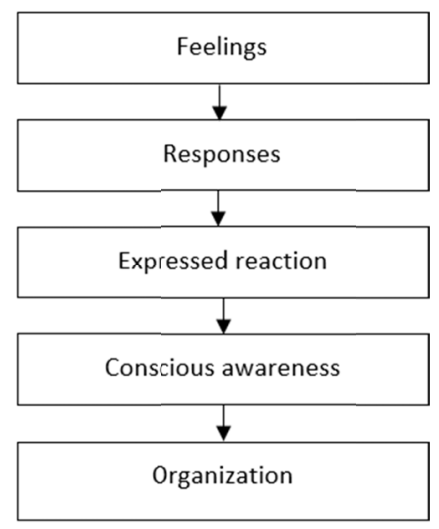

Figure 8. Emotional taxonomy; based on Clarkson et al. (2010, p. 126)

Table 3. Emotional taxonomy with descriptors

\begin{tabular}{ll}
\hline Feelings & $\begin{array}{l}\text { Student has feelings towards a school subject, recognizing that the subject generates } \\
\text { feelings, and the feelings grow to become the student's ... }\end{array}$ \\
\hline Responses & Either positive or negative when lead to a regular and ... \\
\hline Expressed reaction & $\begin{array}{l}\text { to the school subject, together with active searching for a range of pleasurable } \\
\text { experiences, with an increasingly ... }\end{array}$ \\
\hline Conscious awareness & and rationalization of the feelings and the choices made, leading to an ... \\
\hline Organized & $\begin{array}{l}\text { Set of lifestyle choices, maximizing the satisfactory experiences and minimizing the } \\
\text { unsatisfactory experiences }\end{array}$ \\
\hline
\end{tabular}

From Clarkson et al. (2010, p. 126).

Clarkson et al. (2010) used the three taxonomies to develop their theory of MWB, outlined in Figure 9 and detailed in Table 4. This is a top-down, cumulative taxonomy of well-being in what is often considered a difficult subject area, in which affective and emotional dimensions have been shown to play a large role in student achievement (Shernoff et al., 2003; Vandecandelaere et al., 2012).

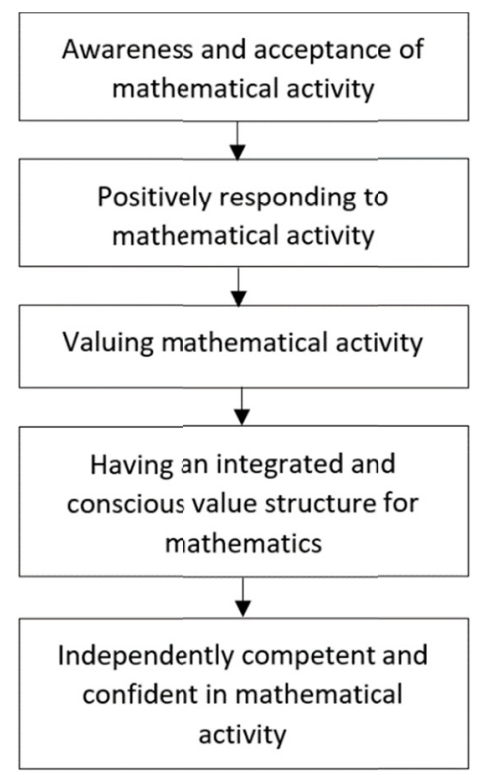

Figure 9. Mathematical well-being (MWB); based on Clarkson et al. (2010) 
Table 4. Mathematical well-being (MWB)

\begin{tabular}{ll}
\hline Stage & Description \\
\hline $\begin{array}{l}\text { 1. Awareness and acceptance of } \\
\text { mathematical activity }\end{array}$ & mathematical activities rather than a coherent body of knowledge \\
& $-\quad$ The learner is aware that the nature of mathematics is different \\
& than other subjects \\
& - The learner recognizes that a mathematical activity is different \\
& from a language or sports activity and it is accepted as a worthwhile \\
& pursuit \\
& - The learner feels comfortable in the mathematical learning context \\
& although the learner is passively accepting of the activity and does not \\
& seek them out
\end{tabular}

\begin{tabular}{ll}
\hline $\begin{array}{l}\text { 2. Positively responding } \\
\text { mathematical activity }\end{array}$ & - Mathematical activity provokes a positive response \\
& $-\quad$ Beyond acceptance, the learner welcomes the activity and feels \\
& pleasure in engaging in the activity and in its achievement \\
& $-\quad$ This pleasure develops feelings of self-confidence and positive \\
& self-esteem \\
& - These feelings reinforce the acceptance and worthwhileness of \\
& mathematical activity in general
\end{tabular}

3. Valuing mathematical activity _ - The learner appreciates and enjoys mathematical activity

- There is an active seeking out of these activities and of people with whom the learner can share the activities

- The learner increases awareness of the human development of mathematical knowledge and the learner's place in mathematics

- The learner achieves acceptable (to them) high levels of mathematical competence

\begin{tabular}{|c|c|}
\hline \multirow[t]{2}{*}{$\begin{array}{l}\text { 4. Having } \\
\text { conscious } \\
\text { mathematics }\end{array}$} & $\begin{array}{l}\text { - The learner is aware of their appreciation of mathematics } \\
\text { - } \quad \text { The learner is aware of how and why they value mathematics } \\
\text { - The learner is aware of where the valuing of mathematics may } \\
\text { lead them in the future }\end{array}$ \\
\hline & $\begin{array}{l}\text { - The learner is confident in their level of skill and competence and } \\
\text { in their ability to judge their own strengths and weaknesses }\end{array}$ \\
\hline \multirow[t]{2}{*}{$\begin{array}{l}\text { 5. Independently competent } \\
\text { confident in mathematical activity }\end{array}$} & $\begin{array}{l}\text { - The learner is fully independent in mathematical activity } \\
\text { - The learner can hold their own in mathematical arguments at } \\
\text { various levels }\end{array}$ \\
\hline & $\begin{array}{l}\text { The learner can criticize the arguments of others from } \\
\text { well-rehearsed criteria }\end{array}$ \\
\hline
\end{tabular}

From Clarkson et al. (2010, p. 127).

One can see from the stage descriptions in Table 4, the influence of OBT-C and OBT-A, as well as the emotional taxonomy in MWB. It is noteworthy that MWB requires a blending of cognitive, affective, and emotional dimensions to fully achieve well-being. It could be postulated that well-being in other subjects could be represented in a similar manner.

The OBT-A taxonomy had far less impact on education than the original cognitive taxonomy (McLeod, 1992). This may have been the case since the dominant theory of learning at the time was behaviorism, which focused on observable constructs, while the affective taxonomy involved internal, non-observable constructs that must be inferred from observable behavior (McLeod, 1992). 
Subsequently, there were several psychomotor taxonomies developed, although without the participation of Bloom. The best known of these taxonomies is Harrow (1972). The psychomotor taxonomies had relatively little impact on education. This may have been due to their narrow focus, as well as some scholarly debates concerning the role of the psychomotor domain (Anderson \& Krathwohl, 2001; Marzano \& Kendall, 2007). One example of an attempt to use the three domains in teaching was Pierce and Gray (1981/2013), though the book had relatively little overall impact, and the OBT-C domain remained the dominant version of OBT until its revision in 2001 by Anderson et al.

\subsection{Revised Bloom's Taxonomy}

In 2001, Anderson et al. published a revision of the OBT-C domain, hereafter referred to as RBT, partially to address criticisms of OBT. RBT is usually considered a bottom-up hierarchical taxonomy based on cognitive demand. Level descriptors were converted to gerunds, some taxa were renamed, and the levels "synthesize" (renamed "create") and "evaluate" were reversed. By far the most important change was the conversion of the taxonomy to a two-dimensional array, with cognitive processes acting on knowledge domains (Figure 10). As with OBT, each level of RBT had sublevels (Figure 11) with accompanying descriptors. The stated focus of the revision was on student learning rather than student performance (Airasian \& Miranda, 2002).

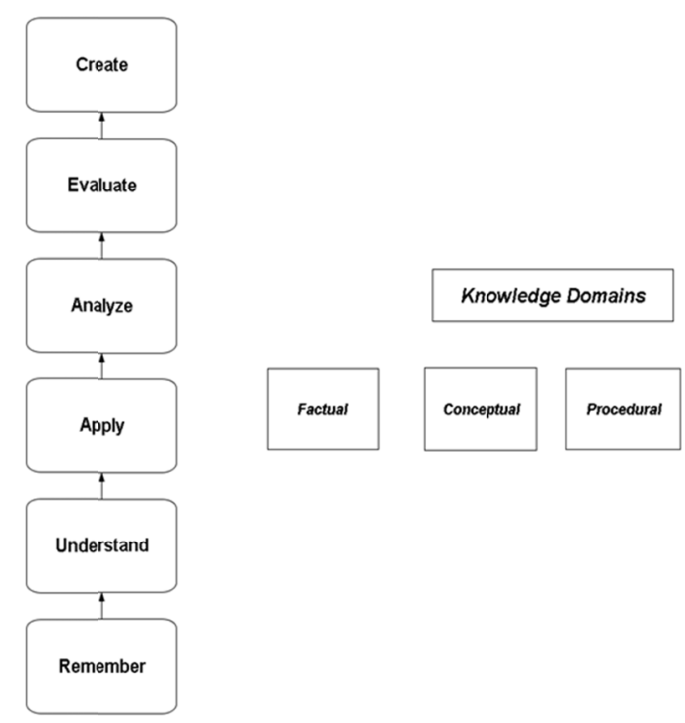

Figure 10. Revised Bloom's taxonomy; based on Anderson et al. (2001)

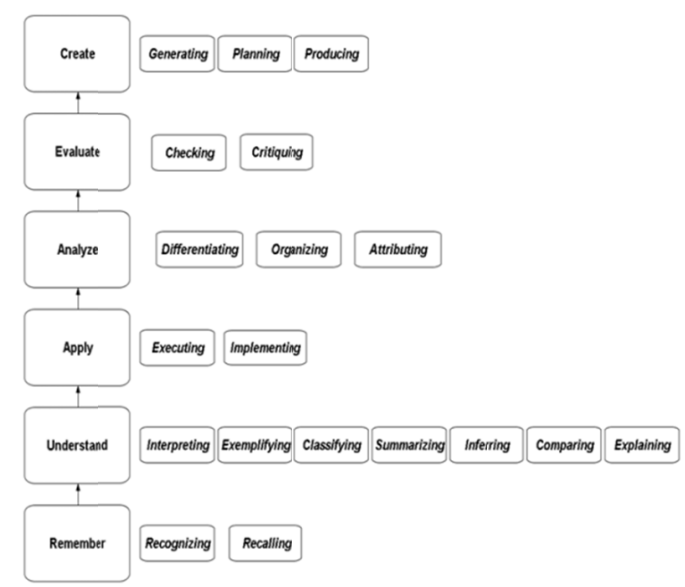

Figure 11. Revised Bloom's taxonomy showing sublevels; from Anderson et al. (2001) 
Anderson et al. (2001) state that the taxa of RBT are discrete, non-overlapping levels, hierarchical based on cognitive demand or cognitive complexity. However, Krathwohl (2002) states that the Comprehension category was renamed Understand, in keeping with teachers' common usage of the latter term. This is somewhat problematic, because "understand" may have a number of levels reflecting the depth of understanding, violating the non-overlapping condition of a taxonomy. This was a concern that Webb (1997, 1999 2002) attempted to address with his Depth of Knowledge taxonomy, discussed later in this paper. As with OBT, RBT is usually assumed to be cumulative, in that completion of lower levels is required for the student to move to higher levels.

An additional concern was the treatment of metacognition. Flavell (1979) separates metacognition into two substrata: declarative knowledge about metacognition, and self-regulation. RBT places metacognition into the knowledge domains, as declarative knowledge to be acted upon by the cognitive processes. This may underserve metacognition (Irvine, 2017a). The active metacognitive substrate of self-regulation is not addressed in RBT.

Similar to OBT, RBT has been used to create learning objectives (Noble, 2004; Polly et al., 2020; Spindler, 2016); to categorize assessment items (Holmes, 2012; Jensen et al., 2014); in course design (Airasian \& Miranda, 2002; Mayer, 2002; Ram et al., 2020); and to identify HOTS (Diacopoulos, 2015; Irvine, 2017a; Narayanan \& Adithan, 2015; Sagala \& Andriani, 2019).

\subsection{SOLO Taxonomy}

The structure of the observed learning outcome (SOLO) taxonomy (Biggs \& Collis, 1982) is a bottom-up, non-hierarchical taxonomy used to evaluate the quality of a student's response to an assessment or evaluation question or task. The quality of the student's understanding of the task can be inferred by analyzing the student's response, based on the SOLO levels (Figure 12).

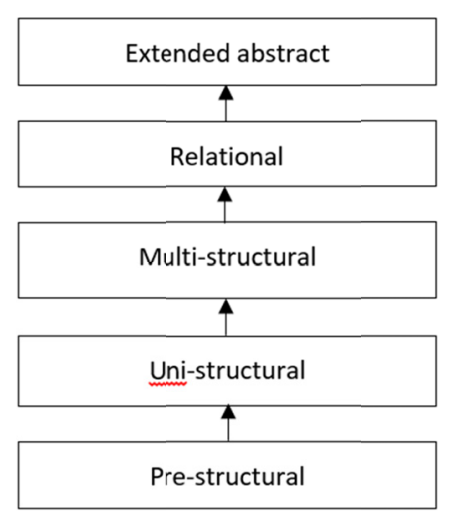

Figure 12. The SOLO taxonomy; from Higgs and Collis (1982)

At the pre-structural level, the response indicates that the student has missed the point of the question. At the uni-structural level, the student's response contains a single set of relevant details. Responses at the multi-structural level contain several strings of details that are unrelated to each other. Relational-level responses integrate sets of relevant details into a coherent overall structure. Finally, at the extended abstract level, the coherent whole of the relational level is generalized or reconceptualized to a higher level of abstraction. The taxonomy moves from basic quantitative responses to higher-order thinking qualitative responses illustrating deep learning (Lucander et al., 2010).

There has been a wide range of applications of the SOLO taxonomy in education. In the original book, Biggs and Collis (1982) indicate how the SOLO taxonomy can be applied to the teaching of history, mathematics, English, and geography. Boulton-Lewis (1994, 1995) has written extensively on applications of SOLO in assessing student learning in higher education. SOLO has been applied to counselling education (Burnett, 1999); marketing (Jaskari, 2013); dentistry education (Lucander et al., 2010); online learning (Shea et al., 2011); accounting (Lucas \& Mladenovic, 2009); and science education (Brabrand \& Dahl, 2009; Newton \& Martin, 2013). Newton and Martin (2013) compared and contrasted the use of SOLO, OBT, and phenomenography as tools for evaluating undergraduate science assessments. 


\subsection{Webb's Depth of Knowledge Levels}

Webb (1997) identified four levels representing the depth of student's knowledge (DOK; Figure 13). This is a bottom-up, non-cumulative taxonomy, although some authors (e.g., Hess, 2004) dispute the term "taxonomy" for DOK.

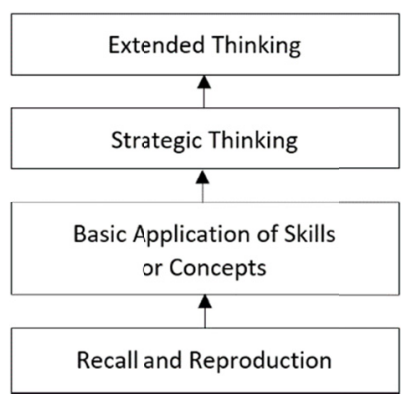

Figure 13. Webb's depth of knowledge (DOK) levels

Level 1, Recall and Reproduction, identifies recall of a fact, term, concept, or principle; perform a routine procedure; locate details. At Level 2, Basic Application of Skills or Concepts, students use information, conceptual knowledge; select appropriate procedures for a task; solve routine problems and problems with two or more steps, including decision points along the way; organize and display data; interpret and use simple graphs; summarize; identify main ideas; explain relationships; make predictions. Level 3, Strategic Thinking, requires reasoning, decision-making or justification; developing a plan or sequence of steps to solve a problem; deal with non-routine problems, complex problems, or abstractions; support judgments with evidence; deal with problems that may have multiple possible answers. At the highest level, Level 4, Extended Thinking, students perform investigations or applications to real-world problems; solve problems requiring research and/or extended time; solve problems with multiple conditions or requiring non-routine manipulations; synthesize information from multiple sources, across content areas or disciplines.

Hess (2012) emphasizes that Webb's DOK corresponds to the depth and complexity of students' learning, not the degree of difficulty of questions. She points out that cognitive taxonomies such as OBT and RBT identify verbs in describing taxa, whereas Webb's DOK is centered on nouns, and what follows the verb. She gives the example of the verb describe, which may be identified with lower levels of OBT and RBT, but may involve very different complexities of thought depending on what follows the verb; simple description of a process versus identifying similarities and differences, or describing the most significant effect of an outcome. Webb's DOK is concerned with how deeply the student must understand the content, based on its complexity or abstractness. Hess (2004a, 2005a, 2012) has developed a cognitive rigor matrix contrasting OBT's levels with Webb's DOK levels. In her matrix Hess argues that each level of OBT can require most or all of Webb's DOK levels, depending on the complexity of the required task.

A major use of DOK is analyzing the alignment of assessment items with state standards (Webb, 1997). Boyles (2016) has outlined how DOK can be used by teachers to deepen students' literacy learning through more questions asked at DOK levels 3 and 4. Hess has indicated how DOK can be applied to a variety of subjects, including reading (2004), writing (2005a), social studies (2005b), science (2010), and mathematics (Petit \& Hess, 2006). Hess's cognitive rigor matrix illustrates how DOK can be integrated with OBT to deepen learning in any subject area (Hess, 2005, 2012; Hess et al., 2009). In a similar way, Harris and Patten (2015) developed a matrix using DOK and RBT in describing learning objectives for cybersecurity topics in a computing course.

\subsection{Fink's Taxonomy of Significant Learning}

Fink (2013) proposed a taxonomy of significant learning (FTSL), based on dissatisfaction with the state of teaching in higher education, and perceived shortcomings or narrowness of existing taxonomies such as OBT and RBT. Fink cites the need for courses in higher education to address such dimensions as metacognition, ethics, leadership and interpersonal skills, communication skills, tolerance, character, and adapting to change. Fink particularly focused on adapting to change, since he viewed change as the imperative of learning (and therefore, 
teaching) in higher education. Figure 14 represents FTSL as a circle, as typically there is no hierarchy proposed for the segments of the circle.

The first taxon is Foundational Knowledge, because there is a need for students to know, remember, and understand information and ideas, which are necessary for other kinds of learning. This is followed by Application, which involves developing and using skills, including: intellectual, physical, or social skills; managing projects; and thinking (critical, creative, and practical). Applications demonstrate the usefulness of other kinds of learning. Integration involves connecting ideas, learning experiences, and life experiences. The ability to make new connections increases students' power. The Human Dimension relates to learning about oneself and others, which allows students to develop their own self-concept as well as self-confidence and the ability to interact more effectively with others. Caring asks students to develop new feelings, interests, and values. Caring about something increases motivation to learn more about that topic and fosters the energy to make that topic a greater part of their lives. The Learning to Learn taxon involves metacognition but also becoming a better student, inquiry into a subject, and developing self-directed learning skills, which together promotes lifelong learning.

Fink (2013) states that his taxonomy is not hierarchical but rather relational and interactive. Gains in one taxon are synergistic with respect to the other taxa, resulting in a dynamic, integrated system of learning. One consequence of utilizing FTSL in course design is that the instructors employ active learning strategies rather than more passive strategies, such as lecture. Stating learning objectives using FTSL promotes greater student involvement in their own learning and recognizes the value of student input in the learning process. However, Foundational Knowledge is clearly the first taxon, because without foundational knowledge it is not possible to address the other taxa. Fink's circular representation of the taxonomy does, however, reinforce the interactive nature of FTSL, in that increases in one taxon has implications for the other taxa.

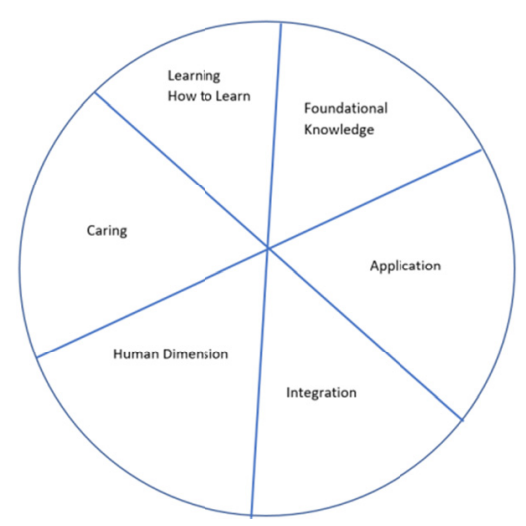

Figure 14. Fink's taxonomy of significant learning (FTSL); from Fink (2013, p. 35)

FTSL has been quite widely utilized in course design in a number of areas, including graduate nursing education (Marrocco, 2014); life span development courses (Fallahi, 2008); health policy courses (Krueger et al., 2011); sustainability engineering (Apul \& Philpott, 2011); and in redesigning an engineering final project (Kusumawardani et al., 2014).

\subsection{Shulman's Table of Learning}

In 2004, Shulman proposed a top-down taxonomy named table of learning (STOL). Shulman's (2004) stated rationale for this new taxonomy was to help organize and categorize important concepts related to learning, and thus stimulate critical reflection, and "call attention to ideas, principles, or values that hitherto have been ignored" (p. 65) In this, Shulman related STOL to his work on pedagogical content knowledge, which arose from identifying a third category of knowledge different than content knowledge and pedagogical knowledge, and relationships among the three concepts.

Shulman's approach is quite theoretical and focuses heavily on a taxonomy as a list of elements to be played with. Shulman conveys the idea that STOL stimulates thought and reveals relationships among the elements of STOL through thoughtful reflection. Figure 15 illustrates STOL, a top-down taxonomy that recognizes the primacy of engagement and motivation in learning. 
The first category in STOL is engagement and motivation. In this, Shulman (2004) recognizes the importance of active learning and student engagement both as motivation to learn as well as a valuable educational outcome in its own right (see, e.g., Irvine, 2020a). The second category, understanding, includes knowledge acquisition but also the ability to paraphrase in one's own words, and the ability to attribute ideas to their original authors. For Shulman, performance and action does not include demonstrating understanding through acts such as essay writing. Rather, performance and action involve interacting with or on the world. Shulman distinguishes between understanding, as a mental activity, and performance, as producing a different set of consequences in the real world. Shulman sees a reciprocal relationship between critical reflection and action, whereby action leads to reflection which in turn may lead to action in a different way or a different direction. Thus, performance and action are linked to reflection and critique.

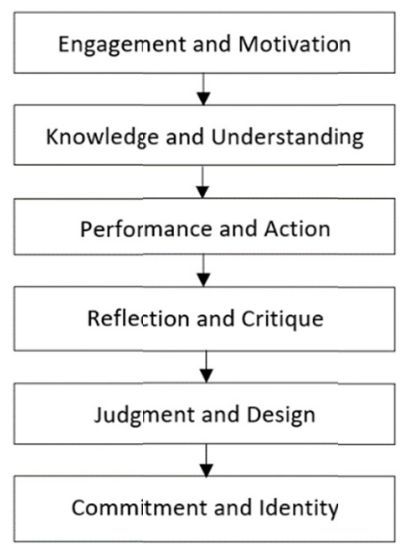

Figure 15. Shulman's table of learning (STOL); from Shulman (2004)

Judgment and design are, in Shulman's (2004) words, “what happens when understanding meets the constraints and complexities of a world" (p. 72) and therefore requires one to judge, adjust, and recognize constraints or limits. The final category is commitment and identity. Shulman views commitment as the ultimate goal of education: "We experience commitment as we internalize values, develop character, and become people who no longer need to be goaded to behave in ethical, moral, or publicly responsible ways" (p. 72).

However, Shulman (2004) discusses at length that STOL is not a finite linear taxonomy and potentially could be represented by a circle, as shown in Figure 16. Achieving commitment and identity fosters renewed engagement and motivation, in what could be termed a continuous learning spiral.

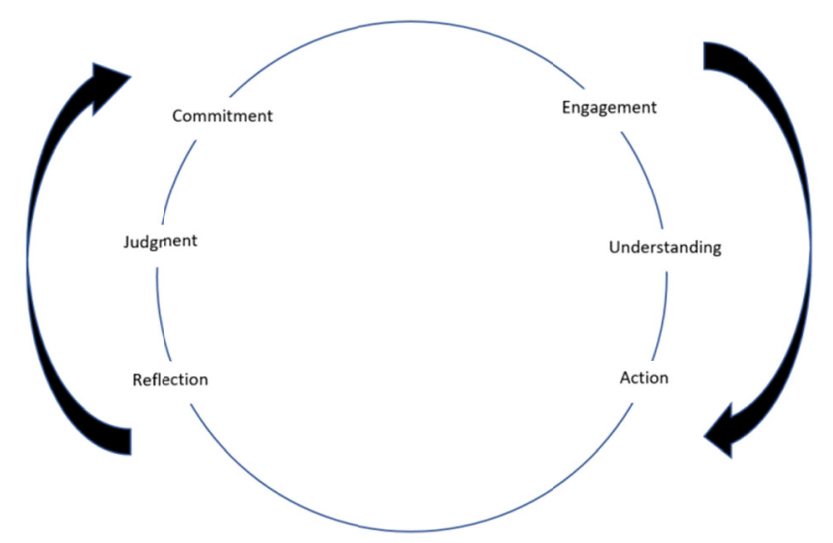

Figure 16. Shulman's conception of continuous learning; from Shulman (2004, p. 75)

Shulman (2004) also viewed the taxa as having paired reciprocal relationships: commitment with engagement, understanding with judgment, and action with reflection. For example, establishing open and less rigid conditions for understanding a concept fosters the need for judgment, which in turn fosters deeper understanding, 
and so on. Reflecting on action may result in different actions, based on judgments about different understanding, which in turn leads to different actions. STOL allows for critical reflection about the relationships among the taxa and hence reconceptualizes STOL in different ways.

A literature search found relatively few instances of STOL being utilized to structure learning outcomes. Mortier and Yatczak (2016) used STOL as a vehicle to understand learning in professional health programs, noting that "The Table of Learning offered us a coherent way of thinking about what we are doing as educators and the impact what we do has on student learning" (p. 88). STOL was used to ensure that the professional programs offered addressed all six taxa in a coherent and logical way. This illustrated the usefulness of taxonomies in course development, learning expectations, and assessment coordination. Goulet and Owen-Smith (2005) in turn applied STOL to physical therapy courses, in the context of cognitive-affective learning, which involves the interaction between the cognitive and affective domains of learning, raising the profile of the affective domain as of equal importance with the cognitive domain, and describes how the two domains are intermingled.

The relative paucity of examples of STOL used in education may reflect the somewhat theoretical stance of Shulman's presentation of STOL. Shulman (2004) very much positioned STOL as a taxonomy representing "elements to be played with" (p. 71), stimulating deeper thought and reflection. It is significant, however, that STOL's first element, engagement and motivation, has become the focus of a large body of research confirming the primacy of engagement and motivation in student learning.

\subsection{Marzano's New Taxonomy}

Marzano's New Taxonomy of Educational Objectives (MNT; Marzano \& Kendall, 2007) is a two-dimensional taxonomy somewhat similar to RBT, although MNT's knowledge domains are somewhat different than RBT (Figure 17).

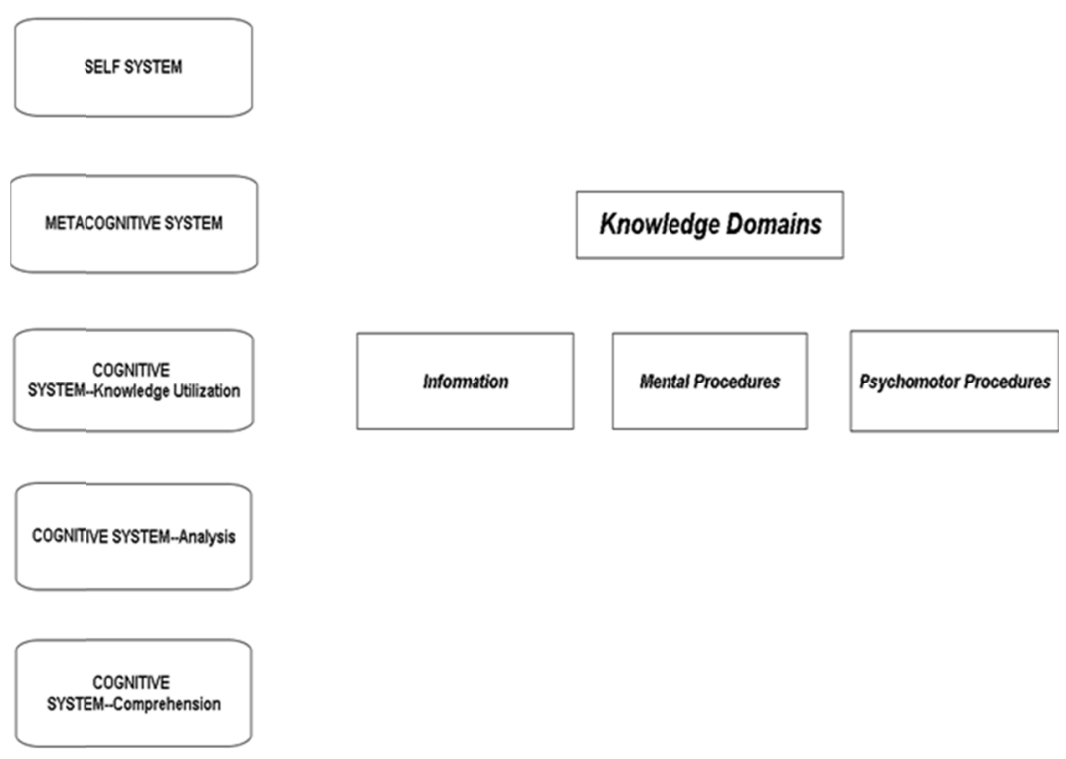

Figure 17. Marzano's new taxonomy (MNT); based on Marzano and Kendall (2007)

MNT's sublevels are shown in Figure 18. The MNT explicitly recognizes the roles of metacognition and affect/self system. Significant differences of MNT and RBT will be discussed later in this paper. MNT is somewhat unique in that it can be considered both a top-down and bottom-up taxonomy. The top two levels (Self system and Metacognitive system) are top-down, while the Cognitive system is bottom-up. Marzano states that MNT is top-down based on both flow of information and level of consciousness required for execution. For example, information initially flows down from the self-system deciding to engage, while knowledge utilization requires greater consciousness than recall of information. This is in keeping with Marzano's theory of learning, shown in Figure 19. 


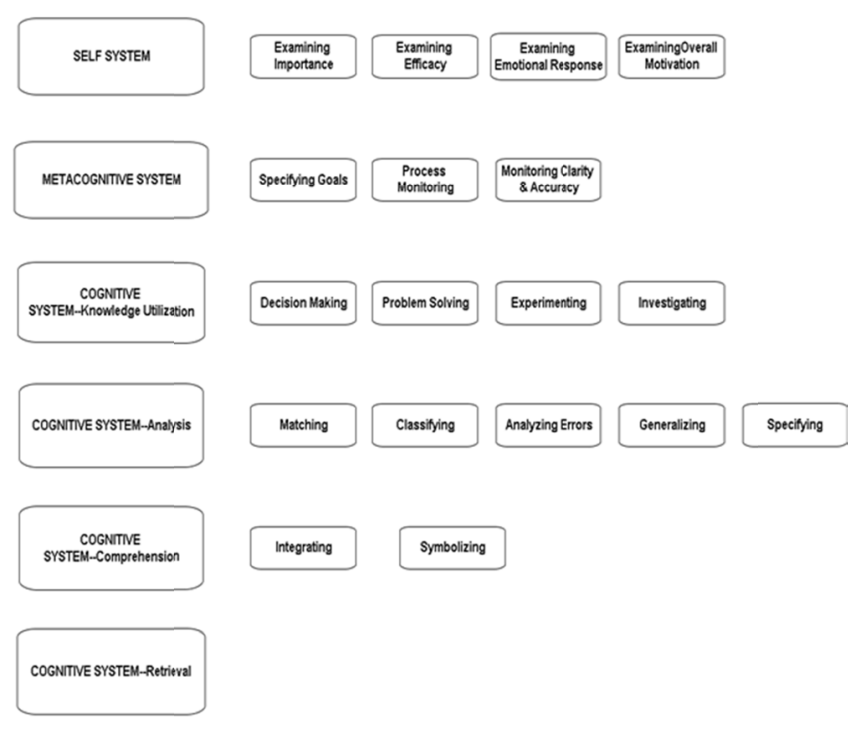

Figure 18. MNT, showing sublevels; based on Marzano and Kendall (2007)

In Marzano's theory of learning, the self system, encompassing motivation, interest, and self-efficacy, involves a decision on whether to engage in a new task. Once the decision to engage is made, the metacognitive system sets goals and develops a strategy. Then the cognitive system engages at whatever level (Figure 19) is appropriate to resolve the task, using knowledge as appropriate for the task.

Marzano and Kendall (2008) published a text on applying MNT in a variety of situations. The text is quite generic and provides basic techniques for applying the taxonomy. MNT has been used extensively to identify HOTS (Afferbach et al., 2015; Dubas \& Toledo, 2016; Faragher \& Huijser, 2014; Insani et al., 2019; Irvine, 2019, 2020a; Toledo \& Dubas, 2016; Zhao, 2011). MNT also has been applied to assessment instruments (Mirzianov et al., 2017; Timofte \& Siminiciuc, 2018); as a framework for investigating student affect (Irvine, 2020a); and to analyze students' critical reflections (Colley et al., 2012). Ironically, Hanna (2007), who used RBT to align course objectives, instruction, and assessment in music education, lamented the omission of an affective dimension in RBT; this omission could have been addressed by using MNT rather than RBT for his analysis.

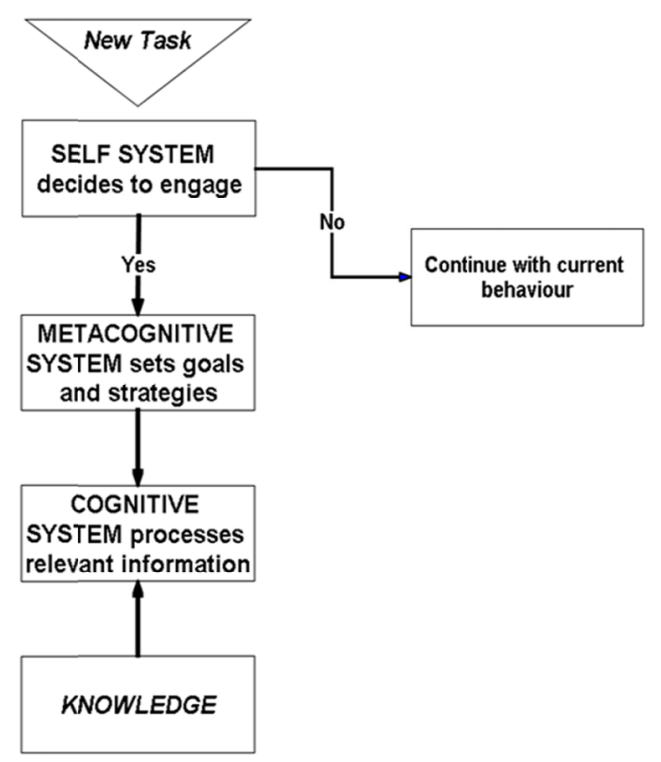

Figure 19. Marzano's theory of learning; from Marzano and Kendall (2007) 


\section{Comparison of the Taxonomies}

This section of the paper will compare and contrast the taxonomies outlined above with respect to their goal or objective, treatment of knowledge, cognition, HOTS, metacognition, affect, and their underlying theories of learning, either explicit or implied.

\subsection{Goals/Objectives}

OBT's original goal was to classify assessment items based on cognitive demand (Bloom et al., 1956). OBT quickly became used for a variety of other purposes, including identifying course objectives; aligning course objectives with instruction and assessment; and identifying HOTS. Bloom et al. (1964) provide broader goals for the OBT-A domain, including classifying assessment items and learning objectives as well as facilitating research and thinking for the affective domain. Bloom et al. indicate that the OBT-A domain was a starting point and that they expected significant modifications and revisions of the taxonomy.

The title of RBT (A Taxonomy for Learning, Teaching, and Assessing; Anderson \& Krathwohl, 2001) implies a much broader objective. Anderson and Krathwohl (2001) state that the revision was undertaken both to reflect and incorporate new knowledge about learning since OBT's publication in 1956 as well as to support the educational community's move to standards-based curriculum, accountability, and authentic assessment. Interestingly, the focus of most of the commentary on RBT has been on the changes to gerunds and the switching of the categories evaluate and synthesize (now create). Relatively less focus has been on the creation of the two-dimensional matrix in which cognitive processes act on knowledge domains. Whether Anderson and Krathwohl achieved their stated objectives regarding learning, teaching, and assessing remains an open question.

The SOLO taxonomy was created to identify quality of learning in a non-subjective way (Biggs \& Collis, 1982) by placing the emphasis on the structure of a student's response rather than strictly on the content. Biggs and Collis (1982) state that the focus of SOLO is on the teaching rather than the learning domain, in that student responses to assessment reflect how well teaching has occurred and the depth to which student learning has progressed based on that teaching, as reflected in the progressive structural complexity of the responses.

Webb's DOK takes a somewhat similar stance to SOLO, in that DOK is a taxonomy used to identify cognitive complexity in both assessment questions as well as student responses. Hess's (2004, 2005a; Hess et al., 2009) discussion of cognitive rigor with respect to DOK clearly identifies distinctions between DOK and OBT, wherein one category of OBT may reflect all four categories of DOK depending on the complexity of the response expected. Webb (1997) indicated that the development of DOK was, at least in part, due to dissatisfaction with the specificity of assessment questions and their relationship to state standards, the latter which might in fact expect deeper student responses, whereas assessment questions that appeared to address a state standard could be satisfied with relatively low-level student responses.

Fink (2013) developed FTSL in response to dissatisfaction with both the quality of university teaching and a perceived paucity of instructional strategies that engage students in their own learning. Fink perceived that many higher education courses required only surface learning of content, with little regard for what he called significant learning experiences. He lamented a concomitant lack of diverse learning experiences in which most university instructors featured lecture or discussion as their primary instructional strategies. Fink claimed that these strategies reinforced the focus on surface learning at the expense of critical thinking and deep learning. FTSL was an attempt to provide alternatives to this surface-level approach to learning, and to identify areas such as citizenship, lifelong learning, metacognition, and affective dimensions that frequently were not addressed.

Shulman (2004) created STOL as "a tool for thought" (p. 65) but also to recognize the primacy of engagement and motivation in learning. STOL was presented less as a structure for application and more as a set of "elements to be played with" (Shulman, 2004, p. 71) and to stimulate scholarly thought. In spite of this original goal, STOL has been applied in a number of subject areas and may have achieved Shulman's goal of stimulating thought among instructors in higher education.

MNT was designed to be a useful tool for educators, with five stated goals seeking to: design and classify educational objectives; design assessments; make state standards more useful to educators; facilitate curriculum design; and serve as a basis for a thinking skills curriculum. Its structure resembles RBT in that there are a set of processes acting on knowledge domains. However, two major differences from RBT are MNT's primacy of the affective/self domain, and the treatment of metacognition as an important, active stage in the learning process. MNT's treatment of engagement and motivation reflects the recognition of the important role that affect plays in learning as well as affective dimensions being learning goals in their own right. 


\subsection{Treatment of Knowledge}

Although the first level of OBT is labelled Knowledge, the taxon actually refers to the lowest level of cognition, namely recognizing and remembering information. The knowledge remembered may involve terminology, facts, concepts; classifications and categories; conventions, trends, principles, generalizations, and theories. However, at the Knowledge level of OBT it is possible that the information may be simply recalled without extensive understanding. OBT Affective domain makes no reference to knowledge, but speaks of affective stimuli and the development of values, the acquisition of which could be construed as acquisition of knowledge.

RBT made a large step forward in clarifying the role of knowledge in learning, by identifying domains of knowledge, which are acted upon by cognitive processes. The RBT knowledge domains are, hierarchically, factual knowledge, conceptual knowledge, procedural knowledge, and metacognitive knowledge. Included in factual knowledge, considered the basic knowledge that students require, are knowledge of terminology as well as specific details and elements. Conceptual knowledge includes classifications and categories, principles and generalizations, theories, models, and structures. Procedural knowledge includes subject-specific skills, algorithms, techniques, and methods-criteria for determining when to use appropriate procedures. Metacognitive knowledge includes strategic knowledge as well as knowledge about cognitive tasks, appropriate contextual and conditional knowledge, as well as self-knowledge. The knowledge domains are considered passive objects acted upon by the cognitive processes.

In the SOLO taxonomy, knowledge is subsumed by the structure of a learner's responses. Biggs and Collis (1982) intentionally identified the quality of learning not by acquisition of particular knowledge but rather by how that knowledge was structured in response to an assessment query. The second and third levels of SOLO discuss how knowledge is used: at Level 2, a single set of details; at Level 3, several sets of unrelated details. SOLO is focused on the use of knowledge rather than the form that the knowledge takes.

Webb's DOK is also focused on the use of knowledge. Level 1, Recall and Reproduction, involves recall of a fact, term, concept, principle, routine procedures, or details; Level 2 comprises Basic Application of Skills or Concepts, in which students use information and conceptual knowledge; organize and display data; and interpret and use simple graphs. DOK's focus is on complexity of thinking rather than on the knowledge elements themselves.

FTSL identifies a taxon as Foundational Knowledge but, similar to OBT, this taxon actually refers to cognitive processes of understanding and remembering knowledge consisting of information and ideas. While FTSL is usually represented by a wheel indicating all categories are equivalent (Figure 14), Fink (2013) makes it clear that "At the base of most other kinds of learning is the need for student to know something" (p. 34). Therefore, Fink perceives Foundational Knowledge as an antecedent of the other taxa, although he also claims that the taxa interact with one another, so that growth in one taxon reciprocally increases the other taxa, including Foundational Knowledge.

STOL's Knowledge and Understanding category is about cognition, with the focus on understanding and the ability to demonstrate that understanding by restating in one's own words the ideas and concepts developed by others. Shulman (2004) does not specify what knowledge involves, but there is an implication that the knowledge goes beyond facts and procedures to include concepts, ideas, and relationships.

\subsection{Cognition}

For all the taxonomies examined, cognition plays a dominant role. Some taxonomies (OBT, RBT, SOLO, DOK) deal exclusively with cognition. For all of these, the cognitive domain is seen as hierarchical bottom-up and sometimes cumulative. For other taxonomies, such as FTSL and STOL, cognition plays an important though not dominant role. FTSL devotes three of six taxa to cognitive dimensions (Foundational Knowledge, Application, Integration). Similarly, in STOL, three of six taxa involve cognition (Knowledge and Understanding; Performance and Action; Judgment and Design). For Marzano, four of six taxa are related to cognition, although MNT places higher value on affect and metacognition. In the earlier times of taxonomic development (e.g., OBT), cognition was seen as the exclusive domain to be taught and examined. As more was learned about how students learn, and recognition was given to other dimensions (such as character development, ethics, and affective concepts), taxonomies began to include some or all of these dimensions, and higher education began to address and assess these concepts.

\subsection{Metacognition}

Flavell (1979) is credited with coining the term metacognition, frequently described as "thinking about thinking." It is not surprising, therefore, that metacognition does not appear in OBT, published in 1956. Metacognitive 
knowledge is included as a knowledge domain in RBT, but this inclusion renders metacognitive knowledge as an inert object to be acted on by the cognitive processes. This is a very narrow treatment of metacognition, which for Flavell included not only declarative knowledge but also the active component of self-regulation. This active dimension is illustrated in Meijer et al.'s (2006) metacognitive taxonomy (Figure 2).

In 2006, the European Union (EU) offered this more inclusive definition of metacognition, with a focus on learning:

Learning to Learn is the ability to pursue and persist in learning, to organize one's own learning, including through effective management of time and information, both individually and in groups. This competence includes awareness of one's learning process and needs, identifying available opportunities, and the ability to overcome obstacles in order to learn successfully. (Erasmus + Strategic Partnership, 2017, para. 2)

According to the $\mathrm{EU}$, metacognition is a key antecedent of lifelong learning, and has five dimensions:

Ability to motivate yourself and to develop your self-esteem.

Ability to reflect learning experiences.

Ability to manage your time.

Ability to organize information.

Ability to learn in groups. (Erasmus+ Strategic Partnership, 2017, para. 4)

Metacognition is not explicitly mentioned in the SOLO taxonomy, although Boulton-Lewis (1994) used the SOLO taxonomy to assess university students' metacognitive knowledge, finding that students' learning strategies became more sophisticated as their responses moved up the SOLO levels. Webb's DOK makes no explicit mention of metacognition, although DOK Level 3, Strategic Thinking, does identify developing a plan or sequence of steps to approach a problem.

FTSL has a taxon called Learning How to Learn, which includes metacognitive concepts such as becoming a better student, inquiring about a subject, and self-directed learning. Metacognition may be inferred in FTSL's Application taxon, particularly in its Thinking subcategory. STOL also implies metacognitive concepts in its taxon Reflection and Critique, although the term metacognition is not explicitly used.

In MNT, metacognition plays a very significant role. Metacognition is seen as an active, critical component of learning, second only to student motivation (the self system). MNT identifies three metacognitive sublevels, specifying goals, process monitoring, and monitoring clarity and accuracy. These omit important dimensions of metacognition included in Meijer et al.'s (2006) taxonomy (Figure 2) such as planning, evaluating, and elaborating. In spite of these omissions, MNT provides the most robust treatment of metacognition in the taxonomies studied.

\subsection{Higher Order Thinking Skills}

Identification of HOTS is one of the most frequent uses of taxonomies. In OBT, HOTS are identified as falling in the upper three taxa (analyze, synthesize, evaluate), and there are many examples of the use of OBT for this purpose. Similarly, RBT's levels of Analyze, Evaluate, and Create are identified as HOTS. However, in RBT's Apply level, the sublevel Implementing "occurs when a student selects and uses a procedure to perform an unfamiliar task" (Anderson \& Krathwohl, 2001p. 78). The reference to an unfamiliar task places this sublevel in HOTS as well.

In the SOLO taxonomy, the top two levels, Relational and Extended Abstract, require HOTS because they go beyond accumulate of information to identify relations among the data and potential abstractions from the data. Similarly, the top two levels of Webb's DOK, Strategic Thinking and Extended Thinking, require HOTS for reasons similar to SOLO.

For FTSL, within the Application taxon, the Thinking (critical, creative, practical) sublevel is indicative of HOTS. As well, the taxon Learning How to Learn can arguably be included in HOTS as it involves metacognitive concepts such as self-directed learning and developing learning strategies. For STOL, the taxa Reflection and Critique as well as Judgment and Design are indicative of HOTS, and elements of the taxon Performance and Action and of the taxon Commitment and Identify can arguably be included in HOTS.

MNT provides a similar identification of HOTS as OBT and RBT; HOTS includes the Metacognitive taxon, all the sublevels of the Knowledge Utilization taxon in Cognition, and the sublevels Generalizing and Specifying of the Cognition level Analysis, because these sublevels refer to situations unfamiliar to the student. 
Clearly, some taxonomies provide a more straightforward method for identifying HOTS: OBT, RBT, SOLO, DOK, and MNT. While FTSL and STOL include concepts related to HOTS, they are less useful for this purpose. It is important to note that only MNT explicitly includes metacognitive concepts in the identification of HOTS.

\subsection{Affect}

OBT produced a separate taxonomy of affect, with resulting minimal impact in education. While it may be useful to disentangle cognition and affect for taxonomic purposes, in actual learning situations the affective and cognitive domains are inextricably intermingled. Initially, affective factors determine whether a student will engage with a learning task (Marzano \& Kendall, 2007; Shuman, 2004). Subsequently, during the learning task, affective factors determine whether the learner continues to engage with the task, will persevere with the task, will confront and surmount difficulties, will enjoy and find interest in the learning, and will reflect on the learning, to question assumptions, to consider alternatives, and to engage in "what if?" questions to address similar and dissimilar situations and engage in near and far transfer of learning. Thus, affective factors are the drivers of learning and the governors of cognition during that learning.

RBT, SOLO, and DOK are solely focused on cognition and make no reference to affective dimensions. Fink (2013) devotes two taxa to affect: Caring (development of feelings, interest, and values) and Human Dimension (learning about oneself and others). It is clear from Fink's stated motives for developing FTSL that affective dimensions were seen as lacking or undervalued in taxonomies extant at the time. For Shulman and Marzano, Affect plays a very important role. Shulman (2004) states

The first item on the list, engagement, is one of the most interesting and important aspects of learning. We rarely paid enough attention to it in the past, but higher education is now much more focused in "active learning" and on evidence that students are engaged in worthwhile educational experiences. (p. 71; italics in original)

Similarly, Marzano places the Self System (affective dimensions) as the top level of MNT (Figure 18), reflecting the recognition, in his view, that motivation and engagement are critical to students' learning. There is abundant research (e.g., Shernoff et al., 2003; Vandecandelaere et al., 2012) on the importance of affective dimensions in student learning.

\subsection{Theories of Learning}

Of the taxonomies reviewed in this paper, Fink, Shulman, and Marzano all explicitly present theories of learning as support or justification of their taxonomies. Fink (2013) explicitly attaches constructivism to his taxonomy. $\mathrm{He}$ is clear that the motive for constructing FTSL was dissatisfaction with what he perceived as stagnant teaching styles in higher education, and content that was not meeting the needs of students nor of the community as a whole. Fink introduced the concept of significant learning to address this perceived need, and associated with FTSL concepts of active learning and students constructing knowledge. The wheel format of FTSL (Figure 14) was intended to indicate that the taxa were relational and interactive, reinforcing each other in symbiotic relationships, whereby gains in one taxon had associated gains in other taxa.

Shulman (2004) presents STOL as an initial starting position for learning and thought. While he indicates a primary position for engagement and motivation (Figure 15), he also recognizes the interactional and relational nature of learning. For example, Figure 16 depicts STOL in a circular reinforcing cycle; commitment reinforces engagement, which leads to greater understanding, and so on through the stages of the taxonomy. Shulman also identifies paired relationships among the taxa. For example, understanding promotes better judgment, which reinforces understanding; reflection modifies action, which leads to further reflection. Shulman (2004) also suggests that judgment and action are critical elements acting on the other four taxa: "knowledge, understanding, analysis and design each need, on the one hand, to be worked upon in a critical and reflective manner via judgment, and, on the other hand, to be enacted in practice as a crucible or reality test for the ideas" (p. 76). Thus, Shulman recognizes the malleable nature of learning, whereby ideas and concepts are formed, tested, and reformed based on evidence or deeper investigation. Shulman clearly presents his taxonomy as a foundation for thought and rearrangement of elements based on further study.

Marzano's theory of learning (Figure 19) identifies the critical role of affect in the learning process. He indicates that without engagement there is no learning. Marzano also indicates that metacognition plays a large part in learning, once the decision to engage has been made. MNT is a top-down taxonomy; however, the cognitive sublevels are not hierarchical; appropriate sublevels will be accessed in order to address the task, based on the plan designed at the metacognitive level, and then appropriate knowledge domains will be accessed to acquire the knowledge needed by the cognitive processes. 
Other taxonomies (OBT, RBT, SOLO, DOK) present no explicit theories of learning. However, all of these taxonomies represent implicit learning theories. OBT, grounded in the era of behaviorism, presents a hierarchical, cumulative, bottom-up theory, in which students must master every lower level in a linear fashion in order to progress up the taxonomy. RBT claims to be "A taxonomy for learning, teaching, and assessing" (Anderson \& Krathwohl, 2001, p. iv), and claims that the linear, bottom-up taxonomy is not necessarily cumulative. However, Anderson et al.'s (2001) presentation of RBT retains the linearity assumption of OBT with respect to learning. DOK and SOLO do not attach theories of learning, although Biggs and Collis (1982) identify the top level of SOLO (Extended Abstract) as a ceiling, not a target for learning. DOK outlines various levels of complexity in learning, but does not identify a particular level as optimal. DOK is more concerned with differentiating learning complexity from learning levels of difficulty.

Very few of the taxonomies include feedback loops, or recognize learning as being non-linear, recursive, emergent, and complex. This is not surprising since presenting a theory of learning was not necessarily the goal of most of these taxonomies. Rather, the taxonomies present ways of organizing and categorizing concepts related to learning, and possibly allowing educators a clearer view of different aspects of the learning process. For a theory of learning that explicitly recognizes the complexity of the learning process, the Pirie-Kieren Model for the Dynamical Growth of Mathematical Understanding (Pierie \& Kieren, 1994) offers an excellent example (Irvine, 2017b). Two dimensions of the Pirie-Kieren model are especially noteworthy, folding back and thickening. Folding back recognizes that learning is non-linear and recursive. Thus, as students learn a concept, they may return to lower levels of the learning process, either to check for understanding, to build additional prior knowledge, or to make informed judgments about their learning at a higher level. Upon returning to a lower level, students retain all knowledge already accumulated at higher levels, which Pirie and Kieren identify as thickening (i.e., students' knowledge upon returning to a lower level is thicker than when they originally left that level). A graphic of the Pirie-Kieren model is shown in Figure 20, and a more detailed discussion of the model can be found in Irvine (2017b). The Pirie-Kieren model could be identified as a taxonomy of learning mathematics; however, Pirie and Kieren chose to refer to it as a model rather than a taxonomy.

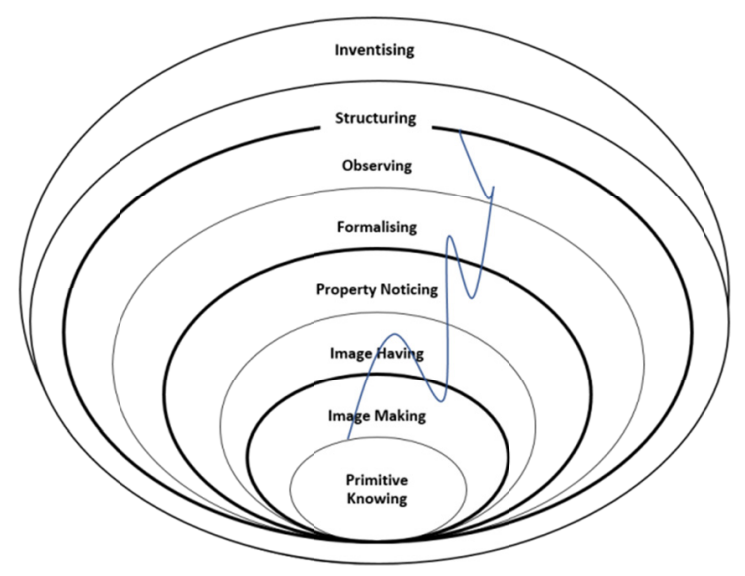

Figure 20. The Pirie-Kieren model for the dynamical growth of mathematical understanding. The jagged line illustrates a possible learning trajectory

\section{Future Directions for Taxonomies in Education}

There is a plethora of taxonomies in education. Most commonly they are used for identifying learning objectives (OBT, RBT, FTSL); for evaluating assessment items (OBT, RBT, DOK, SOLO); for course or curriculum design (RBT, FTSL, STOL); and/or for identifying HOTS, critical thinking, or creative thinking (OBT, RBT, DOK, SOLO, MNT).

Coherent with the growth in knowledge about learning, some taxonomies emphasize the role of affect, engagement, and motivation in learning (MNT, STOL). This trend is likely to continue as we amass evidence that affective dimensions are key to student active engagement in their learning. On a related note, the research in values and their impact on learning is likely to lead to more taxonomies such as DeBellis and Golding (2006; Figure 1). 
Another productive area of research is the blending or combining of taxonomies to produce new understanding. Mathematical well-being is an example of this blending, whereby Clarkson et al. (2010) blended OBT Cognitive domain, OBT Affective domain, and an emotional taxonomy (Figure 8and Table 3) resulting in a taxonomy of mathematical well-being. This remains an active area of research (Clarkson, 2013). Another productive blending of taxonomies is Hess's $(2004,2005 \mathrm{a}$, Hess et al., 2009) blending of OBT and DOK to illustrate the distinction between level of difficulty and level of complexity in learning, and the use of Hess's cognitive rigor matrix in curriculum analysis and design.

Complexity theory and its relation to theories of learning is likely to result in taxonomies reflecting learning as a non-linear, recursive, and emergent activity, such as the Pirie-Kieren model. At a minimum, taxonomies will begin to include explicit feedback loops, recognizing that learning is not relentlessly linear.

It is also likely that more "special purpose" taxonomies will appear (see, e.g., Meijer et al., 2006; Figure 2). Because learning is such a complex activity, taxonomies that assist educators in disentangling specific aspects - even aspects of cognition such as knowledge utilization, ethics, or citizenship - would be useful. It must be remembered, however, that taxonomies representing one aspect of learning do not represent the overall process of learning but rather only one dimension of a complex activity.

\section{Conclusion}

The taxonomies examined in this paper represent the most recognized of a wide variety of available taxonomies extant. OBT is a seminal product that has not only withstood the challenges of time but that also has been applied across a very wide array of areas and subjects. In some ways this is unfortunate because it no longer is representative of current knowledge in the field of learning. However, the publishing of OBT spurred a sea change in education, allowing educators to categorize learning activities and assessments and thus shape future educational curricula. More recent taxonomies reflect the growth in knowledge about learning. FTSL has spurred higher education to critically examine both curricula and instructional strategies. DOK and cognitive rigor has been used extensively to map assessment items to state standards, recognizing that the intended curriculum and the assessed curriculum are not always congruent. Other taxonomies such as MNT, FTSL, and STOL have emphasized that learning cannot be one-dimensionally focused only on cognition but rather must recognize the broad requirements of educating the whole student. Taxonomies will continue to play an important role in supporting educators' understanding of the learning process and its dimensions.

\section{References}

Adams, N. (2015). Bloom's taxonomy of cognitive learning objectives. Journal of the Medical Library Association, 103(3), 152-153. https://doi.org/10.3163/1536-5050.103.3.010

Afferbach, P., Cho, B., \& Kim, J. (2015). Conceptualizing and assessing higher-order thinking in reading. Theory into Practice, 54, 203-212. https://doi.org/10.1080/00405841.2015.1044367

Airasian, P., \& Miranda, H. (2002). The role of assessment in the revised taxonomy. Theory into Practice, 4(4), 249-254. https://doi.org/10.1207/s15430421tip4104_8

Anderson, L., \& Krathwohl, D. (Eds.). (2001). A taxonomy for learning, teaching, and assessing: A revision of Bloom's taxonomy of educational objectives-Complete edition. Addison Wesley Longman.

Apul, D. S., \& Philpott, S. M. (2011). Use of outdoor living spaces and Fink's taxonomy of significant learning in sustainability engineering education. Journal of Professional Issues in Engineering Education and Practice, 137(2), 69-77. https://doi.org/10.1061/(ASCE)EI.1943-5541.0000051

Arievitch, I. (2020). The vision of developmental teaching and learning and Bloom's taxonomy. Learning, Culture and Social Interaction, 27. https://doi.org/10.1016/j.lcsi.2019.01.007

Betts, S. (2008). Teaching and assessing basic concepts to advanced applications: Using Bloom's taxonomy to inform graduate course design. Academy of Educational Leadership Journal, 12(3), 99-106. Retrieved from https://tinyurl.com/53yr9u6n

Biggs, J., \& Collis, K. (1982). Evaluating the quality of learning: The SOLO taxonomy (Structure of the Observed Learning Outcome). Academic Press. https://doi.org/10.1016/C2013-0-10375-3

Bloom, B. S., Engelhart, M. D., Furst, E. J., Hill, W. H., \& Krathwohl, D. R. (1956). Taxonomy of educational objectives: The classification of educational goals-Handbook I, cognitive domain. David McKay.

Bloom, B. S., Krathwohl, D. R., \& Masia, B. B. (1964). Taxonomy of educational objectives: The classification of educational goals-Handbook II, affective domain. David McKay. 
Boulton-Lewis, G. (1994). Tertiary students' knowledge of their own learning and the SOLO taxonomy. Higher Education, 28, 387-402. https://doi.org/10.1007/BF01383724

Boulton-Lewis, G. (1995). The SOLO taxonomy as a means of shaping and assessing learning in higher education. Higher Education Research and Development, 14(2), 143-154. https://doi.org/10.1080/0729436950140201

Boyles, N. (2016). Pursuing the depths of knowledge. Educational Leadership, 74(2), 46-50. Retrieved from https://educacion.udd.cl/files/2016/12/Pursuing-depths-knowledge.pdf

Brabrand, C., \& Dahl, B. (2009). Using the SOLO taxonomy to analyze competence progression of university science curricula. Higher Education, 58, 531-549. https://doi.org/10.1007/s10734-009-9210-4

Burnett, P. (1999). Assessing the structure of learning outcomes from counselling using the SOLO taxonomy: An exploratory study. British Journal of Guidance and Counselling, 27(4), 567-580. https://doi.org/10.1080/03069889908256291

Clarkson, P. (2013, January). A paradox? Students' mathematical well-being [Poster presentation]. Mathematics Educational Research Unit seminar series, Ottawa, ON, Canada. Retrieved from http://meru-urem.ca/2013-5/

Clarkson, P., Bishop, A., \& Seah, W. T. (2010). Mathematics education and student values: The cultivation of mathematical wellbeing. In T. Lovat, R. Toomey, \& N. Clement (Eds.), International research handbook on values education and student wellbeing (pp. 111-135). Springer. https://doi.org/10.1007/978-90-481-8675-4_7

Colley, B., Bilics, A., \& Lerch, C. (2012). Reflection: A key component to thinking critically. The Canadian Journal for the Scholarship of Teaching and Learning, 3(1), Article 2. https://doi.org/10.5206/cjsotl-rcacea.2012.1.2

DeBellis, V., \& Golding, G. (2006). Affect and meta-affect in mathematical problem solving: A representational perspective. Educational Studies in Mathematics, 63(2), 131-147. https://doi.org/10.1007/s10649-006-9026-4

Diacopoulos, M. (2015). Untangling Web 2.0: Charting Web 2.0 tools, the NCSS guidelines for effective use of technology and Bloom's taxonomy. The Social Studies, 106(4), 139-148. https://doi.org/10.1080/00377996.2015.1015711

Dictionary.com. (n.d.). Dictionary.com. Retrieved March 15, 2021, from https://www.dictionary.com/browse/taxonomy

Dollarhide, C. T. (2013). Techniques for spiritual, ethical, and religious counselling: Using a values-based taxonomy in counselor education. Counselling and Values, 58(2), 221-236. https://doi.org/10.1002/j.2161-007X.2013.00035.x

Dubas, J., \& Toledo, S. (2016). Taking higher order thinking seriously: Using Marzano's taxonomy in the economics classroom. International Review of Economics, 21, 12-20. https://doi.org/10.1016/j.iree.2015.10.005

Erasmus+ Strategic Partnership. (2017). About IG4L2L. Retrieved from http://www.learntolearn.eu/

Fallahi, C. (2008). Redesign of a life span development course using Fink's taxonomy. Teaching of Psychology, 35(3), 169-175. https://doi.org/10.1080/00986280802289906

Faragher, L., \& Huijser, H. (2014). Exploring evidence of higher order thinking skills in the writing of first year undergraduates. The International Journal of the First Year in Higher Education, 5(2), 33-44. https://doi.org/10.5204/intjfyhe.v5i2.230

Fink, L. D. (2013). Creating significant learning experiences: An integrated approach to designing college courses, revised and updated. Jossey-Bass.

Flavell, J. (1979). Metacognition and cognitive monitoring: A new area of cognitive-developmental inquiry. American Psychologist, 34(10), 906-911. https://doi.org/10.1037/0003-066X.34.10.906

Goulet, C., \& Owen-Smith, P. (2005). Cognitive-affective learning in physical therapy education: From implicit to explicit. Journal of Physical Therapy Education, 19(3), 67-72. https://doi.org/10.1097/00001416-200510000-00009 
Hanna, W. (2007). The new Bloom's taxonomy: Implications for music education. Arts Education Policy Review, 108(4), 7-16. https://doi.org/10.3200/AEPR.108.4.7-16

Harris, M., \& Patten, K. (2015). Using Bloom's and Webb's taxonomies to integrate emerging cybersecurity topics into a computing curriculum. Journal of Information Systems Education, 26(3), 219-236. Retrieved from https://tinyurl.com/2nd87w44

Harrow, A. J. (1972). A taxonomy of the psychomotor domain: A guide for developing behavioral objectives. McKay.

Harvard University. (2003). Balanced assessment: Transition \& middle school tasks. Teachers' College Press.

Hess, K. (2005b). Exploring cognitive demand in instruction and assessment. NCIEA. Retrieved from https://www.nciea.org/publications/DOK_ApplyingWebb_KH08.pdf

Hess, K. (2011). A new lens for examining cognitive rigor in standards, curriculum, and assessments: What are some implications for the transition to Common Core State Standards? [PowerPoint slides]. NCIEA. Retrieved from https://www.nciea.org/publications/rigorpresentation_KH11.pdf

Hess, K. K. (2004, August). Applying Webb's depth-of-knowledge (DOK) levels in reading. NCIEA. Retrieved from https://www.nciea.org/publications/DOKreading_KH08.pdf

Hess, K. K. (2005a). Applying depth of knowledge (DOK) levels in writing. NCIEA. Retrieved from https://www.nciea.org/publications/DOKwriting_KH08.pdf

Hess, K. K. (2005b). Applying Webb's depth-of-knowledge (DOK) levels in social studies. NCIEA. Retrieved from http://www.nciea.org/publications/DOKsocialstudies_KH08.pdf

Hess, K. K. (2005c). Exploring cognitive demand in instruction and assessment. NCIEA. Retrieved from https://www.nciea.org/publications/DOK_ApplyingWebb_KH08.pdf

Hess, K. K. (2010). Applying Webb's depth-of-knowledge (DOK) levels in science. NCIEA. Retrieved from https://www.nciea.org/publications/DOKscience_KH11.pdf

Hess, K. K. (2012). A new lens for examining cognitive rigor in standards, curriculum, \& assessments: What are some implications for the transition to Common Core State Standards? NCIEA. Retrieved from https://www.nciea.org/publications/rigorpresentation_KH11.pdf

Hess, K. K., Jones, B. S., Carlock, D., \& Walkup, J. R. (2009). Cognitive rigor: Blending the strengths of Bloom's taxonomy and Webb's depth of knowledge to enhance classroom-level processes. NCIEA. Retrieved from https://files.eric.ed.gov/fulltext/ED517804.pdf

Holmes, V. (2012). Depth of teachers' knowledge: Frameworks for teachers' knowledge of mathematics. Journal of STEM Education, 13(1), 55-71. Retrieved from https://tinyurl.com/m4vac6nn

Insani, M., Pratiwi, N., \& Muhardjito, M. (2019). Higher-order thinking skills based on Marzano taxonomy in basic biology I course. Journal Pendidikan Biologi Indonesia, 5(3), 521-528. https://doi.org/10.22219/jpbi.v5i3.10171

Irvine, J. (2017a). A comparison of revised Bloom and Marzano's new taxonomy of learning. Research in Higher Education Journal, 33, Article 1. Retrieved from https://eric.ed.gov/?id=EJ1161486

Irvine, J. (2017b). From description to prescription: A proposed theory of teaching coherent with the Pirie-Kieren model for the dynamical growth of mathematical understanding. Journal of Instructional Pedagogies, 17, Article 5. Retrieved from https://tinyurl.com/yd5pyr25

Irvine, J. (2019). Opportunities to address metacognition and higher-order thinking skills when we teach trigonometry. OAME Gazette, 58(2), 45-48. Retrieved from https://tinyurl.com/yuxr93y2

Irvine, J. (2020a). Marzano's new taxonomy as a framework for investigating student affect. Journal of Instructional Pedagogies, 24, 4-34. Retrieved from https://eric.ed.gov/?id=EJ1263740

Irvine, J. (2020b). Positively influencing student engagement and attitude in mathematics through an instructional intervention using reform mathematics principles. Journal of Education and Learning, 9(2), 48-75. https://doi.org/10.5539/jel.v9n2p48

Irvine, J., Telford, W., Anusic, V., \& Alves, P. (2016). A straightforward model eliciting activity (MEA) and the power of What If? Questions in supporting students' higher-order thinking. Journal of Mathematical Sciences, 3(1), 7-22. Retrieved from https://tinyurl.com/hbn7uj83 
Jaskari, M. (2013). The challenge of assessing creative problem solving in client-based marketing development projects: A SOLO taxonomy approach. Journal of Marketing Education, 35(1), 231-244. https://doi.org/10.1177\%2F0273475313485586

Jensen, J., McDaniel, M., Woodard, S., \& Kummer, T. (2014). Teaching to the test...or testing to teach: Exams requiring higher order thinking skills encourage greater conceptual understanding. Educational Psychological Review, 26, 307-329. https://doi.org/10.1007/s10648-013-9248-9

Johansson, E. (2020). The assessment of higher-order thinking skills in online EFL courses: A quantitative content analysis. Nordic Journal of English Studies, 19(1), 224-256. http://doi.org/10.35360/njes.519

Kantar, L. (2014). Assessment and instruction to promote higher order thinking in nursing students. Nurse Education Today, 34(5), 789-794. https://doi.org/10.1016/j.nedt.2013.08.013

Kim, M., Patel, R., Uchizono, J., \& Beck, L. (2012). Incorporation of Bloom's taxonomy into multiple-choice examination questions for a pharmacotherapeutics' course. American Journal of Pharmaceutical Education, 76(6), 114-124. https://doi.org/10.5688/ajpe766114

Krathwohl, D. R. (2002). A revision of Bloom's taxonomy: An overview. Theory into Practice, 41(4), 212-218. https://doi.org/10.1207/s15430421tip4104_2

Krippendorff, K. (2013). Content analysis: An introduction to its methodology (3rd ed.). Sage.

Krueger, K., Russell, M., \& Bischoff, J. (2011). A health policy course based on Fink's taxonomy of significant learning. American Journal of Pharmaceutical Education, 75(1), 1-7. https://doi.org/10.5688/ajpe75114

Kusumawardani, S., Nugroho, L., Susanto, A., Kumara, A., Suryo, H., \& Cortes, U. (2014). Reducing student's learning duration on engineering final project by implementing Fin's taxonomy on e-learning. Journal of Theoretical and Applied Information Technology, 68(3), 699-704. Retrieved from http://www.jatit.org/volumes/Vol68No3/27Vol68No3.pdf

Lucander, H., Bondemark, L., Brown, G., \& Knutsson, K. (2010). The structure of observed learning outcome (SOLO) taxonomy: A model to promote dental students' learning. European Journal of Dental Education, 14, 145-150. https://doi.org/10.1111/j.1600-0579.2009.00607.x

Lucas, U., \& Mladenovic, R. (2009). The identification of variation in students' understandings of disciplinary concepts: The application of the SOLO taxonomy within introductory accounting. Higher Education, 58, 257-283. https://doi.org/10.1007/s10734-009-9218-9

Madhuri, G., Kantamreddi, V., \& Prakash Goiteti, L. (2012). Promoting higher order thinking skills using inquiry-based learning. European Journal of Engineering Education, 37(2), 117-123. https://doi.org/10.1080/03043797.2012.661701

Marrocco, G. (2014). Fostering significant learning in graduate nursing education. Journal of Nursing Education, 53(3), 177-179. https://doi.org/10.3928/01484834-20140223-02

Marzano, R., \& Kendall, J. (2007). The new taxonomy of educational objectives (2nd ed.). Corwin Press.

Marzano, R., \& Kendall, J. (2008). Designing and assessing educational objectives: Applying the new taxonomy. Corwin Press.

Mayer, R. (2002). A taxonomy for computer-based assessment of problem solving. Computers in Human Behavior, 18(6), 623-632. https://doi.org/10.1016/S0747-5632(02)00020-1

McBain, R. (2011). How high can students think? A study of students cognitive levels using Bloom's taxonomy in social studies (ED524386). ERIC. Retrieved from https://eric.ed.gov/?id=ED524386

McLeod, D. (1992). Research on affect in mathematics education: A reconceptualization. In D. Grouws (Ed.), Handbook of research on mathematics teaching and learning (pp. 575-595). Macmillan.

Meijer, J., Veenman, M., \& Van Hout-Wolters, B. (2006). Metacognitive activities in text-studying and problem solving: Development of a taxonomy. Educational Research and Evaluation, 12(3), 209-237. https://doi.org/10.1080/13803610500479991

Meissner, R., Jenatschke, D., \& Thor, A. (2020, October). Evaluation of approaches for automatic e-assessment item annotation with levels of Bloom's taxonomy. In C. Pang, Y. Gao, G. Chen, E. Popescu, L. Chen, T. Hao, B. Zhang, S. M. B. Navarro, \& Q. Li (Eds.), Learning technologies and systems (Vol. 12511, pp. 57-69). https://doi.org/10.1007/978-3-030-66906-5_6 
Mortier, T., \& Yatezak, J. (2016). Utilizing Shulman's table of learning to understand learning in professional health science programs. Journal of the Scholarship of Teaching and Learning, 16(6), 85-105. https://doi.org/10.14434/josotl.v16i6.20074

Morton, D., \& Colbert-Getz, J. (2017). Measuring the impact of the flipped anatomy classroom: The importance of categorizing as assessment by Bloom's taxonomy. Anatomical Sciences Education, 10(2), 170-175. https://doi.org/10.1002/ase.1635

Muzyk, A. J., Lentz, K., Green, C., Fuller, S., May, D. B., \& Roukema, L. (2017). Emphasizing Bloom's affective domain to reduce pharmacy students' stigmatizing attitudes. American Journal of Pharmaceutical Education, 81(2), Article 35. https://doi.org/10.5688/ajpe81235

Narayanan, S., \& Adithan, M. (2015). Analysis of question papers in engineering course with respect to HOTS (higher order thinking skills). American Journal of Engineering Education, 6(1), 1-10. https://doi.org/10.19030/ajee.v6i1.9247

Newton, G., \& Martin, E. (2013). Blooming, SOLO taxonomy, and phenomenography as assessment strategies in undergraduate science education. Journal of College Science Teaching, 43(2), 78-90. https://doi.org/10.2505/4\%2Fjcst13_043_02_78

Noble, T. (2004). Integrating the revised Bloom's taxonomy with multiple intelligences: A planning tool for curriculum differentiation. Teachers College Record, 106(1), 193-211. https://doi.org/10.1111/J.1467-9620.2004.00328.X

Oliver, D., Dobele, T., Greber, M., \& Roberts, T. (2004). Comparing course assessments: When lower is higher and higher, lower. Computer Science Education, 14(4), 321-341. https://doi.org/10.1080/0899340042000303465

Pappas, E., Pierrakos, G., \& Nagel, B. (2013). Using Bloom's taxonomy to teach sustainability in multiple contexts. Journal of Cleaner Production, 48, 54-64. https://doi.org/10.1016/j.jclepro.2012.09.039

Petit, M., \& Hess, K. (2006). Applying Webb's depth of knowledge and NAEP levels of complexity in mathematics. NCIEA. Retrieved from http://www.nciea.org/publications/DOK_KH08.pdf

Pierce, W., \& Gray, C. (2013). Teaching in the three domains of learning: The taxonomies simplified for educational objectives, activities and outcomes. University Press of America. (Original work published 1981)

Pirie, S., \& Kieren, T. (1994). Growth in mathematical understanding: How can we characterise it and how can we represent it?. Educational Studies in Mathematics, 26, 165-190. https://doi.org/10.1007/BF01273662

Polly, D., Byker, E., Putman, S., \& Handler, L. (2020). Preparing elementary education teacher candidates to teach with technology: The role of modeling. Journal of Digital Learning in Teacher Education, 36(4), 250-265. https://doi.org/10.1080/21532974.2020.1795953

Polya, G. (1957). How to solve it: A new aspect of mathematical method. Doubleday.

Puentedura, R. (2006). Transformation, technology, and education. Retrieved from http://hippasus.com/resources/tte/

Puentedura, R. (2009, February). As we may teach: Educational technology, from theory into practice. Retrieved from http://hippasus.com/blog/archives/25

Ram, M., Ajay, K., \& Nair, A. (2020). Geoscience curriculum approach through learning taxonomy and outcome based education. Higher Education for the Future, 7(1), 22-44. https://doi.org/10.1177\%2F2347631119886403

Sagala, P., \& Andriani, A. (2019). Development of higher-order thinking skills (HOTS) questions of probability theory subject based on Bloom's taxonomy. Journal of Physics, Conference Series, 1188(1), 120-125. https://doi.org/10.1088/1742-6596/1188/1/012025

Shea, P., Gozza-Cohen, M., Uzuner, S., Mehta, R., Valicheva, A., Hayes, S., \& Vickers, J. (2011). The community of inquiry framework meets the SOLO taxonomy: A process-product model of online $\begin{array}{llll}\text { learning. Educational Media International, } & \text { 48(2), }\end{array}$ https://doi.org/10.1080/09523987.2011.576514

Shernoff, D., Csikszentmihalyi, M., Schneider, B., \& Shernoff, E. (2003). Student engagement in high school classrooms from the perspective of flow theory. School Psychology Quarterly, 18(2), 158-176. https://doi.org/10.1521/scpq.18.2.158.21860 
Shulman, L. (2004). Teaching as community property: Essays on higher education. Jossey-Bass.

Spindler, M. (2016). Assessing learning objectives with Bloom's revised taxonomy. NACTA Journal, 60(3), 348-349.

Timofte, R., \& Siminiciuc, L. (2018). Utilisation of Rasch model for the analysis of an instrument developed by mapping items to cognitive levels of Marzano taxonomy. Acta Didactica Napocensia, 11(2), 71-78. https://doi.org/10.24193/ADN.11.2.6

Toledo, S., \& Dubas, J. (2016). Encouraging higher-order thinking in general chemistry by scaffolding student learning using Marzano's taxonomy. Journal of Chemical Education, 93(1), 64-69. https://doi.org/10.1021/acs.jchemed.5b00184

Tyran, C. (2010). Designing the spreadsheet-based decision support systems course: An application of Bloom's taxonomy. Journal of Business Research, 63(2), 207-216. https://doi.org/10.1016/j.jbusres.2009.03.009

Ugur, H., Constantinescu, P., \& Stevens, M. (2015). Self-awareness and personal growth: Theory and application of Bloom's taxonomy. Eurasian Journal of Educational Research, 60, 89-110. https://doi.org/10.14689/EJER.2015.60.6

Van de Heyde, V., \& Siebrits, A. (2019). Higher-order assessment for physics in the digital age using Sakai. Physics Teacher, 57(1), 32-34. https://doi.org/10.1119/1.5084925

Vandecandelaere, M., Speybroeck, S., Vanlaar, G., Fraine, B., \& Van Damme, J. (2012). Learning environment and students' mathematics attitude. Studies in Educational Evaluation, 38(3-4), 107-120. https://doi.org/10.1016/j.stueduc.2012.09.001

Webb, N. (1997). Criteria for alignment of expectations and assessments in mathematics and science education (Research Monograph No. 6). National Institute for Science Education. Retrieved from https://eric.ed.gov/?id=ED414305

Webb, N. (1999). Alignment of science and mathematics standards and assessments in four states. Research Monograph No. 18. National Institute for Science Education. Retrieved from https://eric.ed.gov/?id=ED440852

Webb, N. (2002, December). Alignment study in language arts, mathematics, science and social studies of state standards and assessments for four states. Council of Chief State School Officers.

Zhao, G., Wang, Q., \& Xu, N. (2011, September). Thinking training aims to develop students' high-order thinking skills: Analyse the essence of thinking training from the view of Marzano new educational objectives taxonomy [Conference session]. 2011 International Conference on Electrical and Control Engineering, Yichang, China. https://doi.org/10.1109/ICECENG.2011.6056887

\section{Copyrights}

Copyright for this article is retained by the author(s), with first publication rights granted to the journal.

This is an open-access article distributed under the terms and conditions of the Creative Commons Attribution license (http://creativecommons.org/licenses/by/4.0/). 